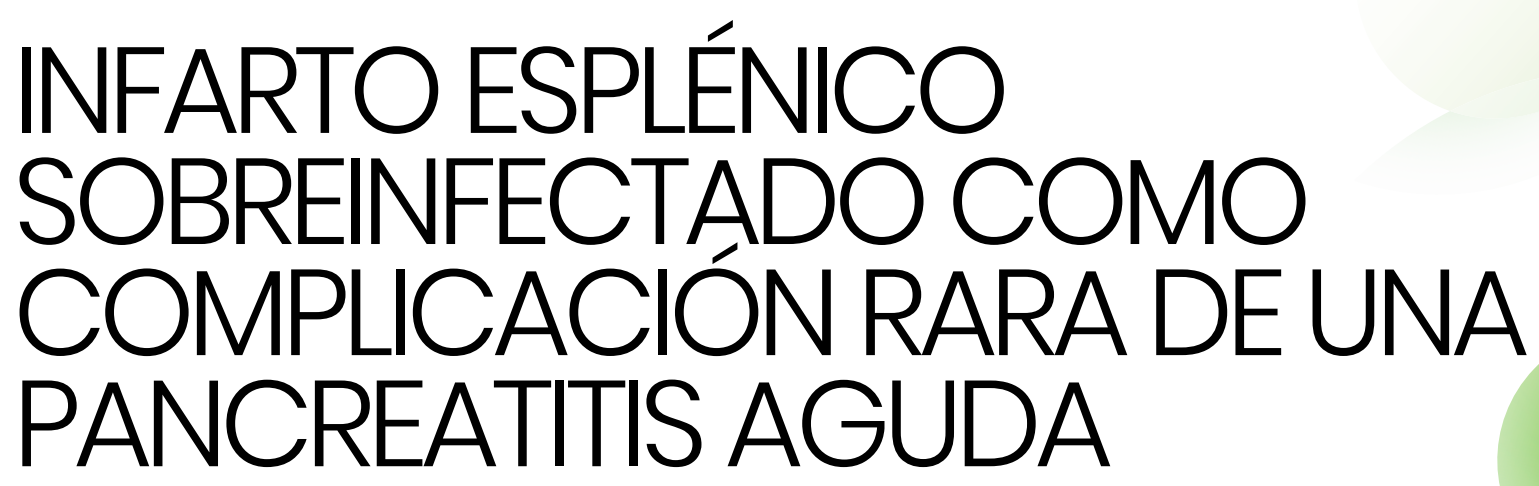

\title{
SUPERINFECTED SPLENIC INFARCTION AS A RARE COMPLICATION OF ACUTE PANCREATITIS
}

\section{Garrido Márquez I, García Pérez PV, Olmedo Sánchez E}

Hospital Universitario Clínico San Cecilio. Granada.

Resumen

El infarto esplénico es una complicación rara presente en el $7 \%$ de las patologías inflamatorias pancreáticas. Existen tres posibles mecanismos patogénicos: una lesión vascular (trombosis venosa o espasmo vascular); compresión directa de los vasos o parénquima esplénicos por un pseudoquiste pancreático y la autodigestión tisular por liberación de enzimas proteolíticas.

Su alta mortalidad hace que deba diagnosticarse y tratarse de forma precoz.

Palabras clave: infarto esplénico, pancreatitis, bazo, tomografía computarizada.

CORRESPONDENCIA

Irene Garrido Márquez

Hospital Universitario Clínico San Cecilio

18016 Granada

igamar26@gmail.com

Fecha de envio: 28/07/2021

Fecha de aceptación: 20/08/2021
Abstract

Splenic infarction is a rare complication present in $7 \%$ of pancreatic inflammatory diseases. There are three possible pathogenic mechanisms: a vascular lesion (venous thrombosis or vascular spasm); direct compression of splenic vessels or parenchyma by a pancreatic pseudocyst and tissue self-digestion by release of proteolytic enzymes.

Its high mortality means that it must be diagnosed and treated early.

Keywords: splenic infarction, pancreatitis, spleen, computer tomography.

\section{Introducción}

El infarto esplénico es una complicación que cada vez se describe con más frecuencia en relación con procesos inflamatorios pancreáticos, debido a la estrecha relación anatómica del páncreas con el bazo y el hilio esplénico. No obstante, es una complicación 
rara de las pancreatitis agudas $(7 \%)^{1,2}$, pero que se debe conocer, diagnosticar y tratar precozmente por su alta tasa de mortalidad.

\section{CASO CLÍNICO}

Presentamos un paciente varón de 69 años con antecedentes personales de HTA, EPOC e insuficiencia renal crónica que acude por dolor abdominal irradiado a flanco izquierdo, con sospecha inicial de diverticulitis aguda que no se confirma mediante prueba de imagen, donde únicamente se observa una lesión quística en cola pancreática sugerente de pseudoquiste (Figura 1). Tras un mes, vuelve a consultar por el mismo motivo junto a alteración

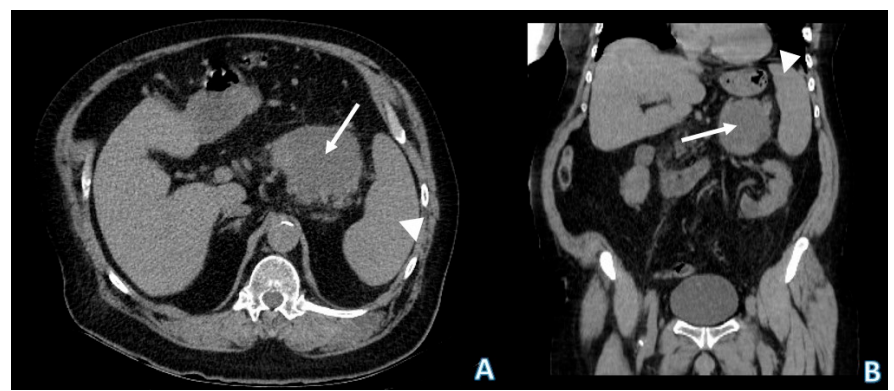

\section{Figura 1}

Imágenes de TC abdominopélvica sin contraste intravenoso en cortes axial (A) y coronal (B). Se observa una colección líquida de pared gruesa y unos $8,5 \mathrm{~cm}$ de tamaño en cuerpo y cola de páncreas, sugerente de pseudoquiste pancreático (flechas). Bazo normal (cabezas de flecha).

del comportamiento, hallándose en la analítica lipasa de $480 \mathrm{U} / \mathrm{L}$ y amilasa de $580 \mathrm{U} / \mathrm{L}$. Se solicita una tomografía computarizada (TC) abdominopélvica con contraste intravenoso para valoración, no visualizando el bazo e identificando en su lecho una colección líquida con gas en su interior que, dado que el paciente no tenía antecedentes de esplenectomía, podría estar en relación con infarto esplénico completo con abscesificación del mismo (Figura 2).

Se ingresa a cargo de la Unidad de Cuidados Intensivos (UCI) y se interviene quirúrgicamente realizándose esplenectomía total con crecimiento posterior de Enterococus Faecalis y Candida Krusei. Durante la cirugía también se observan signos de pancreatitis aguda con algún foco necrótico. La Anatomía Patológica identifica restos de parénquima esplénico con necrosis de coagulación completa por infarto agudo isquémico con licuefacción.

El paciente fue tratado mediante ventilación mecánica, hemodiafiltración veno-venosa continua, heparina de $13 \mathrm{ml} / 7 \mathrm{~h}$ y antibioterapia (ampicilina $1000 \mathrm{mg} / 24 \mathrm{~h}$, imipenem $4 \mathrm{~g} / 24 \mathrm{~h}$ y caspofungina $70 \mathrm{mg} / 24 \mathrm{~h}$ ), pero termina falleciendo diez días después de su ingreso en $\mathrm{UCl}$.

\section{DISCUSIÓN}

El infarto esplénico es una complicación rara presente en el $7 \%$ de las patologías inflamatorias pancreáticas ${ }^{1,2}$, si bien podemos encontrarla en otros órganos. Así, se han descrito complicaciones vasculares en la pancreatitis aguda, necrosis renal cortical, infarto esplénico, cardiopatía isquémica, isquemia cerebral e infarto de la retina ${ }^{2}$

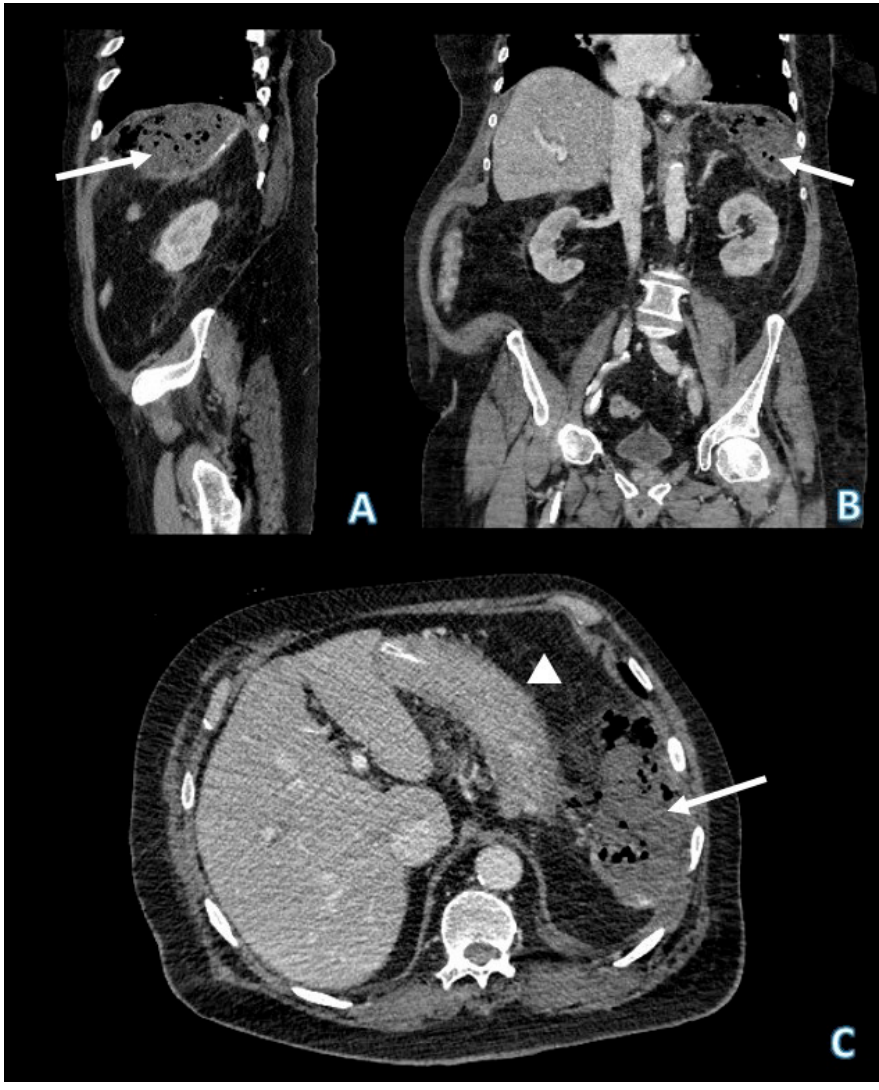

Figura 2

TC abdominopélvica con contraste intravenoso en fase portal, cortes sagital (A), coronal (B) y axial (C), realizada un mes después de la anterior. Ausencia de bazo y presencia en su lecho de colección (flechas) con burbujas de gas en su interior y en íntima relación con la curvatura mayor gástrica (cabeza de flecha), sin clara comunicación con su luz. Dada la ausencia de antecedente de esplenectomía, sugiere infarto esplénico con sobreinfección del mismo y formación de absceso.

En relación con la afectación del bazo, se ha descrito asociación con leucemia mieloide crónica y mielofibrosis en un $50-72 \%$ de los casos, aunque también con anemias hemolíticas, estados de hipercoagulabilidad, desórdenes embólicos (fibrilación auricular y endocarditis), enfermedades vasculares, traumatismos, complicaciones quirúrgicas (pancreatectomía y trasplante hepático) y otras causas poco frecuentes como trombosis de la vena esplénica, amiloidosis, sarcoidosis y síndrome de distrés respiratorio del adulto $^{3,4}$.

Existen tres posibles mecanismos patogénicos: una lesión vascular (trombosis venosa o espasmo vascular por extensión directa del proceso inflamatorio local o hipercoagulabilidad); la compresión directa de los vasos o parénquima esplénicos por un pseudoquiste pancreático y la autodigestión tisular por liberación de enzimas proteolíticas ${ }^{1}$.

El síntoma más frecuente es el dolor en hipocondrio izquierdo, que puede acompañarse de fiebre, escalofríos, náuseas y vómitos, dolor pleurítico y dolor en hombro izquierdo (signo de Kher). 
Su alta mortalidad hace que deba diagnosticarse y tratarse de forma precoz ${ }^{2}$.

Para su diagnóstico, las pruebas de imagen juegan un papel esencial, siendo de elección la TC abdominopélvica con contraste intravenoso en fases arterial y portal. En algunos casos se podrá visualizar claramente el defecto de repleción en los vasos esplénicos (arteria o vena) compatible con trombosis o bien una estenosis de los mismos, con la consecuente alteración de la densidad del parénquima esplénico y signos inflamatorios en vecindad como líquido libre y aumento de densidad de la grasa. Además, en el caso que hemos presentado, se asocia una sobreinfección esplénica debido a que el parénquima del bazo se sustituye completamente por una colección líquida con burbujas de gas en su interior, hallazgos en relación con absceso.

Entre sus diagnósticos diferenciales cabe destacar el hematoma subcapsular y la rotura esplénica. En estos casos, la TC evidenció un aumento del tamaño del bazo con una colección subcapsular hipodensa así como hemoperitoneo asociado (líquido libre de alta densidad) ${ }^{5}$.

El pronóstico varía en relación al proceso responsable del infarto esplénico ${ }^{2}$.

El principal objetivo del tratamiento médico es la analgesia con narcóticos o antiinflamatorios no esteroideos, estando la cirugía indicada solo en caso de complicaciones. En general, la mayoría de los infartos esplénicos no requieren tratamiento quirúrgico. Las indicaciones de tratamiento quirúrgico son: sepsis, absceso, hemorragia y formación de pseudoquiste ${ }^{2,6}$.

\section{Conclusión}

Aunque el infarto esplénico es una complicación rara de la pancreatitis aguda, debemos conocer su existencia y sospecharlo ante un empeoramiento del paciente, así como sus manifestaciones en las pruebas de imagen, para así poder realizar un diagnóstico y tratamiento precoces debido a su alto riesgo de mortalidad.

\section{Bibliografía}

1. Martín-Lagos Maldonado A, Ruiz-Escolano E, Alcázar-Jaén LM, et al. Infarto esplénico masivo secundario a una pancreatitis aguda grave. RAPD Online 2012; 35(4):281-2.

2. Arenal Vera JJ, Said A, Guerro A, et al. Infarto esplénico secundario a pancreatitis aguda. Rev Esp Enferm Dig. 2008; 100(5):300-3.

3. Nores M, Phillips EH, Morgenstern L, Hiatt JR. The clinical spectrum of splenic infarction. Am Surg 1998; 64:182-8.

4. Unstun C, Kutlar F, Holley L, Seigler M, Burgess R, Kutlar A. Interaction of sickle cell trait with hereditary spherocytosis: Splenic infarcts and sequestration. Acta Hematol 2003; 109:46-9.

5. Rial Justo X, García-Oria Serrano MJ, Muñoz Rodríguez JM, García Pavía A, Remírez Arriaga X, Román García de León L, et al. Rotura esplénica espontánea en pancreatitis aguda. Presentación de un caso. Rev Acircal. 2018; 5(2):66.

6. Jaroch MT, Broughan TA, Hermann RE. The natural history of splenic infarction. Mt Sinai J Med 1997; 64: 342-9. 